officials have increasingly come to realize that it often fails in the larger test of picking the best science. During the past decade, as Japan has struggled with a stagnant economy, international patent disputes and competition from an emergent China, officials have repeatedly sought to make Japanese researchers stronger on the international scene by upping the competition at the domestic level.

Those efforts have not always paid off - for example, plans to double competitive funding between 2001 and 2005 fell short because the economy couldn't keep up and the science budget plateaued. But change may now be afoot with the massive $¥ 100$-billion (US\$1.1 billion) Funding Program for World-Leading Innovative R\&D on Science and Technology (FIRST) - a plan that was slashed by the new government last year, but that is nevertheless handing out some of the biggest competitive grants Japanese researchers have ever seen (see page 966). The 30 winning scientists will now have four years to spend an average of $¥ 3.3$ billion each, and will enjoy much greater autonomy under this 'researcher-focused' plan than that offered by previous grant programmes.

FIRST represents an ambitious and worthwhile step for Japan. However, the programme could have been better planned. Consider, for example, that most of the 30 FIRST winners are already worldleading innovators - they include a Nobel laureate and some of the top-cited scientists in their fields. The majority of them were already

"The government should make sure that the country's basic foundations for science are in good repair - and that it is seeking out the most creative projects." the recipients of significant grants, and four have been leaders or co-leaders at one of the five World Premier International Research Centers - a 2007 initiative intended to attract top-quality scientists from around the world to work with their Japanese counterparts. These outstanding researchers have accomplished much, and will undoubtedly accomplish more. But it would have been encouraging to see some new faces. Because Japan's strategy for world-class innovation rewards researchers solely on the basis of their past success, it runs the risk of missing some excellent ideas from younger, lessestablished researchers.

It is also worth asking whether all of these projects require such huge investment. Some clearly do - one example being the Hitachi corporation's effort to develop a holographic electron microscope. This could open a new window onto atomic structures, thereby benefiting hundreds of researchers in various fields. But it is less clear whether all of the FIRST projects will be able to make such productive use of their massive budgets.

A proportion of the FIRST money might arguably have been better spent on increasing the pot of money available through the alreadyexisting mechanism for doling out small competitive grants: the 'Grants-in-Aid' programme administered by one of the country's leading research funding agencies, the Japan Society for the Promotion of Science. Such funding is crucial for small groups hoping to look into risky but potentially groundbreaking ideas - the way that many of the FIRST project leaders made the major discoveries that led them to fame. Moreover, the Grants-in-Aid programme has been forced to cut the average size of its awards in recent years, from $¥ 3.34$ million in 2003 to $¥ 2.89$ million in 2008 , because Japan’s overall research budgets have remained flat even as the country tries to support an increasing number of researchers. That surge was created, in part, by a programme launched in 1995 that successfully produced thousands of new postdocs but didn't find them jobs (see Nature 449, 1084-1085; 2007).

These concerns aside, however, Japan's government and research community must now follow through on FIRST, giving these projects the support and participation they need to realize their full value. But the next time the government invests large sums in competitive funding, it should first make sure that the country's basic foundations for science are in good repair - and that it is truly seeking out the most creative projects. They are not always in the obvious places.

\section{Welcome Nature Communications}

ince the launch of Nature Genetics in 1992, the number of Nature
research journals has grown to 16 - the most recent, Nature
Chemistry, was launched a year ago. This month sees the launch of the seventeenth: Nature Communications.

All of the previous Nature research journals have focused on a particular discipline or community of research interests. Their aim is to publish the most original and scientifically impact-making research appropriate to those particular audiences. Their high ranking in the citation league tables would suggest that this goal is generally being fulfilled.

Nature Communications differs in being multidisciplinary. It aims not to compete with the established Nature journals, but to publish rigorous and comprehensive papers that represent advances of significance to specialists within each field. In addition, it welcomes submissions in fields that are not represented by a dedicated Nature research journal - for example, developmental biology, plant science, microbiology, ecology and evolution, palaeontology, astronomy and high-energy physics (see go.nature.com/xJzuY5). Readers will find in the launch issue papers on topics including classical and quantum correlations under decoherence; a candidate gene for mechanoreception in Drosophila sensory cilia; a strategy to obtain sequence-regulated vinyl copolymers using metal-catalysed step-growth radical polymerization; how a ritualized vibratory signal evolved from locomotion in territorial caterpillars; and more besides.

Like all Nature journals, it is editorially independent. It is also the first Nature research journal to be funded in hybrid fashion: by both subscriptions and optional authors' fees that allow instant free access to their published papers. (It is our publishers' policy to keep subscription rates of hybrid journals under review to reflect the volume of content that is behind the subscription firewall.) Furthermore, it is the first Nature journal to be launched entirely without a print edition: its content is available only online.

Nature welcomes this distinctive new sibling publication - this time, serving the whole research community. 